Original Research Paper

\title{
Efficacy of the Administration of a Natural Feed Supplement in the Management of Equine Gastric Ulcer Syndrome in 7 Sport Horses: A Field Trial
}

\author{
${ }^{1}$ Stucchi Luca, ${ }^{1}$ Zucca Enrica, ${ }^{2}$ Serra Alessia, ${ }^{1}$ Stancari Giovanni, \\ ${ }^{1}$ Ceriotti Serena, ${ }^{3}$ Conturba Bianca, ${ }^{1}$ Ferro Elisabetta and ${ }^{1}$ Ferrucci Francesco \\ ${ }^{1}$ Department of Health, Animal Science and Food Safety (VESPA), Università degli Studi di Milano, Italy \\ ${ }^{2}$ Private Practitioner, Alessandria, Italy \\ ${ }^{3}$ Centro Clinico-Veterinario e Zootecnico Sperimentale, Università degli Studi di Milano, Italy
}

\author{
Article history \\ Received: 31-03-2017 \\ Revised: $15-05-2017$ \\ Accepted: 15-06-2017 \\ Corresponding Author: \\ Ferrucci Francesco \\ Department of Health, Animal \\ Science and Food Safety \\ (VESPA), Università degli \\ Studi di MIlano, Italy \\ Phone: +3902 503.31112 \\ Fax: + 3902503.31115 \\ E-mail: francesco.ferrucci@unimi.it
}

\begin{abstract}
Equine Gastric Ulcer Syndrome (EGUS) is one of the most common causes of poor performance in the equine patient and affects more than $90 \%$ of Standardbred and Thoroughbred racehorses in training. Nowadays, the principal therapeutic options for EGUS treatment include antiacids such as histamine receptor antagonists and proton pump inhibitors. Recently, many studies concerning feed supplements to treat and prevent EGUS were carried out. The aim of the present study was to evaluate the efficacy of a natural feed supplement, administered for 30 days, as the only treatment for gastric ulcerations in sport horses in training. Seven horses were selected for the study on the basis of their gastroscopic evidence of erosive and ulcerative lesions of the gastric mucosa. Each horse received a natural feed supplement (Gastrocure, Institute Farmaceutico Candioli, Italy) registered for use in horses for 30 days. Gastroscopy was performed on day $0\left(\mathrm{~T}_{1}\right)$, day $15\left(\mathrm{~T}_{2}\right)$ and at the end of the treatment (day $30, \mathrm{~T}_{3}$ ). Scores were assigned according to MacAllister method (score 0,1,2,3,4 for number of lesions and score $0,1,2,3,4,5$ for lesion severity). Statistical analysis showed a strong evidence $(p<0.01)$ of lower scores occurring at $T_{3}$ when compared to T1for both number and severity of gastric lesions. In conclusion, the administration of Gastrocure was effective in reducing the number and severity of ulcerative lesions in horses affected by EGUS.
\end{abstract}

Keywords: Horse, EGUS, Gastroscopy, Feed Supplement

\section{Introduction}

Equine Gastric Ulcer Syndrome (EGUS) is one of the most common causes of poor performance in the equine patient and affects more than $90 \%$ of Standardbred and Thoroughbred racehorses in training (Ferrucci et al., 2003a; Roy et al., 2005; Bell et al., 2007). EGUS also affects horses involved in others disciplines such as endurance (Tamzali et al., 2011), show horses (White et al., 2007) and horses not involved in competition, such as broodmares (Le Jeune et al., 2009). EGUS is associated with several risk factors, i.e., stress (Malmkvist et al., 2012), intense training and competition (Roy et al., 2005; Jonsson and Egenvall, 2006) and diet (Nadeau et al., 2003; Andrews et al., 2008). EGUS has a negative impact on horse's health and performance. The most common clinical sings are weight loss (Murray et al., 1989; Dionne et al., 2003), poor performance (Nieto et al., 2009) and gastrointestinal symptoms (Andrews and Nadeau, 1999; Dionne et al., 2003). EGUS treatment aims to promote ulcers healing, eliminate clinical signs and prevent the onset of recurrences (Buchanan and Andrews, 2003). The therapeutic approach includes management strategies and drugs administration (Hepburn, 2001; Sykes and Jokisalo, 2015). The first aim of pharmacological therapy is to suppress acid secretion. Nowadays, the principal therapeutic options for EGUS treatment include antiacids such as histamine receptor antagonists andproton pump inhibitors. All these products are effective although a "rebound effect" is frequently reported and this could exacerbate the syndrome (Hunfeld et al., 2007) furthermore, they are expensive and should be administered for long periods of time. Besides, in sport horses, most treatments during the competition periodsare not permitted.These considerations led to an increased interest in research forless expensive 
natural alternatives to prevent the deleteriouseffects of increased acidity and recurrence of gastric ulcers after discontinuing omeprazole administration. For these reasons, many studies concerning feed supplementsto treat and prevent gastric ulceration in horses were carried out (Venner et al., 1999; Ferrucci et al., 2003b; Huff et al., 2012; Hellings and Larsen 2014).

The aim of the present study was to evaluate the efficacy of a natural feed supplement, administered for 30 days, as the only treatment for gastric ulcerations in sport horses in training.

\section{Materials and Methods}

\section{Horses}

All procedures performed on horses were approved by the University of Milan Ethics Committee (Protocol Number 72/14) and included informed owner consent.

Seven sport horses were selected for the study on the basis oftheir gastroscopic evidence of erosive and ulcerative lesions of the gastric mucosa. The study population consisted in four Thoroughbreds (three mares and one gelding), two Standardbreds (one mare and one gelding) and one Arabian gelding. All horses were in full training either for flat (thoroughbreds and standardbreds) or endurance (ara bian gelding) racing. All horses ranged in age from three to fifteen years old (mean age: $6.6 \pm 5.5$ years) and had a mean weight of $440 \pm 34.5 \mathrm{~kg}$. All the horses were stabled in individual boxes and bedded on woods having. Racehorses (thoroughbreds and standardbreds) were fed approximately $8 \mathrm{~kg}$ hay and 7 $\mathrm{kg}$ commercial pelleted feed per daywith free access to drinking water and engaged in race once monthly. Endurance horse was fed $10 \mathrm{~kg}$ hay and $5 \mathrm{~kg}$ commercial pelletedand raced once every two month. Feeding was not changed in the competition period.

\section{Physical Examination}

A physical examination was performed on all horses before the beginning of the study in order to rule out the presence of any clinical disease. Behaviour and physical parameters (rectal temperature, pulse, respiratory rate, gut motility) were monitored at weekly intervals throughout the study.

\section{Gastroscopic Examination}

Gastroscopy was performed onday $0\left(\mathrm{~T}_{1}\right)$, day $15\left(\mathrm{~T}_{2}\right)$ and at the end ofthe treatment (day $30, \mathrm{~T}_{3}$ ). Before gastroscopic examination, feed was withheld for $24 \mathrm{~h}$. All horses were examined with a video gastro scope (PV-G 34-325; Storz, Germany) connected to an aspirator pump (208-ACH; Faset, Italy). Horses were restrained with a twitch and sedated with $0.01 \mathrm{mg} / \mathrm{kg}$ i.v. hydrochloride detomidine (Detogesic; Zoetis, USA). To enable observation of the squamous mucosa, margoplicatus and glandular mucosa, the stomach was insufflate with air. Recordings of gastroscopic examinations were reviewed independently by three examiners with different level of experience. Scores were assigned according to MacAllister method (score $0,1,2,3,4$ for number of lesions and score $0,1,2,3,4,5$ for lesion severity, MacAllister et al., 1997).

\section{Treatment}

Each horse received natural feed supplement (Gastrocure, Institute Farmaceutico Candioli, Italy) registered for use in horses (Table 1) according to the producer indications: 85 grams orally twice daily forten days and then 85 grams once daily for twenty days were administered. During this period, the management factors, such as feeding and training regimen, were not changed.

\section{Statistical Analysis}

Data were analyzed by a categorical response linear regression, considering the ulcer number andseverity scores as dependent variables. The probability for each score was estimated both for number and for severity. Moreover, in the regression model it was kept into account that each subject was repeatedly scored-on three occasions (times)-by three evaluators for each occasion.

Time, with three increasing levels (1, 2 and 3), was considered as the regression independent variable.

Both for number and severity of lesions, the hypothesis of higher probability of lower scores (cut off: $\leq 2$ ), comparing $\mathrm{T}_{3}$ with $\mathrm{T}_{1}$, was tested at $\mathrm{p}<0.05$ level of significance.

Statistical analysis was performed with SAS STATC software (SAS Institute Inc., Cary, NC, USA).

\section{Results}

Throughout the study, the horses didnot show any signs of discomfort and all the monitored parameters remained within normal limits. The product was well accepted by all of the horses and no side effects were observed.

Gastroscopy at $T_{1}$ showed that all horses had gastric lesions localised tothe squamous mucosa close to the margoplicatus. Four horses had ulcers active bleeding. Only three horses showed lesions of the glandular mucosa. The average scores regarding number and severity of lesions of the three operators at $T_{1}, T_{2}$ and $T_{3}$ are showed in Fig. 1.

Statistical analysis showed a strong evidence ( $p<0.01$ ) of lower scores occurring at $\mathrm{T}_{3}$ when compared to $\mathrm{T}_{1}$ (Fig. 2 and 3 ).

When the cut off was considered, for the number of lesions probability of $\leq 2$ score increased from 0.04 to 0.35 between time 1 and time 3 ( 0.31 increment) (Fig. 4). For the severity of lesions, probability of $\leq 2$ score increased from 0.36 to 0.76 between time 1 and time 3 (0.40 increment) (Fig. 5). 
Table 1. Composition and analytical constituents of feed supplement

\section{Composition}

Alfalfa hay, Soybean kernel, Saccharose, Calcium Carbonate, Oils and Vegetable Fats (Soybean Oil), Magnesium Hydroxide, Methil-Sulphonil-Methane.

Additives for kg: Vitamins and Pro-vitamins (Vitamin E/alpha-tocopheryl-acetate g 2,5).

Emulsifiers and Stabilizing Agents: Guar Gum g 75.

Natural products: Plantago ovate (Fleawort extract) g 19; Trigonellafoenum-graecum (Fenugreek extract CoE 460) g 13; Aloe Vera (Aloe extract CoE 28) g 6; Glycyrrhizaglabra (Licorice extract CoE 218) g 10;

Aminoacid: L-threonine g 63;

Preservatives: Methyl-4-hydroxibenzoate E218 g 0,23; Propile-4-hydroxibenzoate E216 g 0,12;Potassium sorbate E202 g 0,35;

Butil-hydroxi-toluene E321 g 0,20

Analytical constituents

Water content

Crude protein

Crude oils and fats

Crude ashes

AshInsoluble in $\mathrm{HCl}$

Crude fiber

Calcium

Magnesium

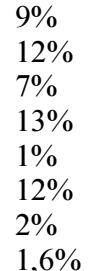

9\%

$13 \%$

$1 \%$

$2 \%$

$1,6 \%$

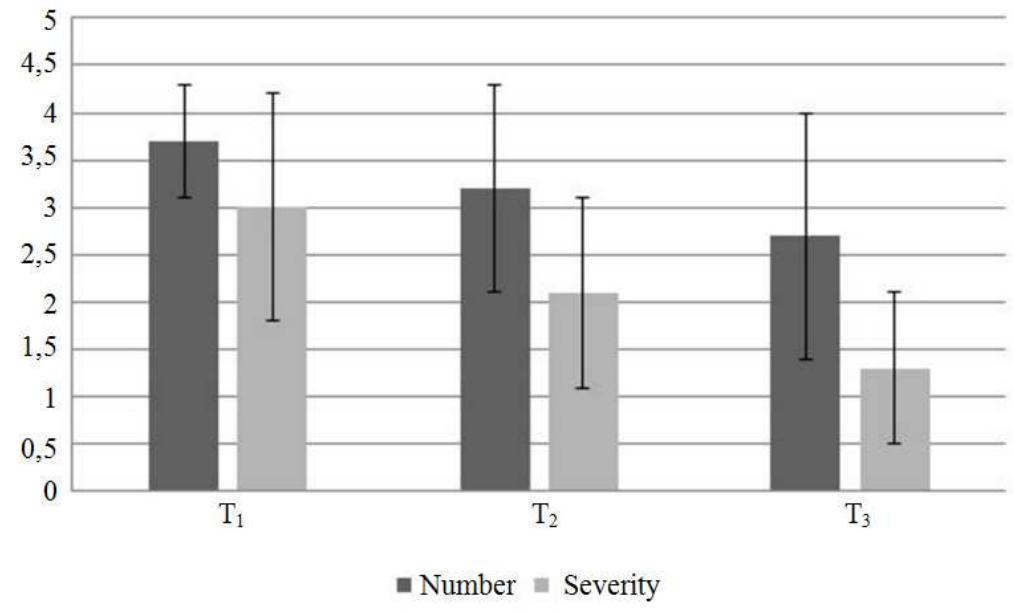

Fig. 1. Average score regarding number and severity of lesions of the three operators

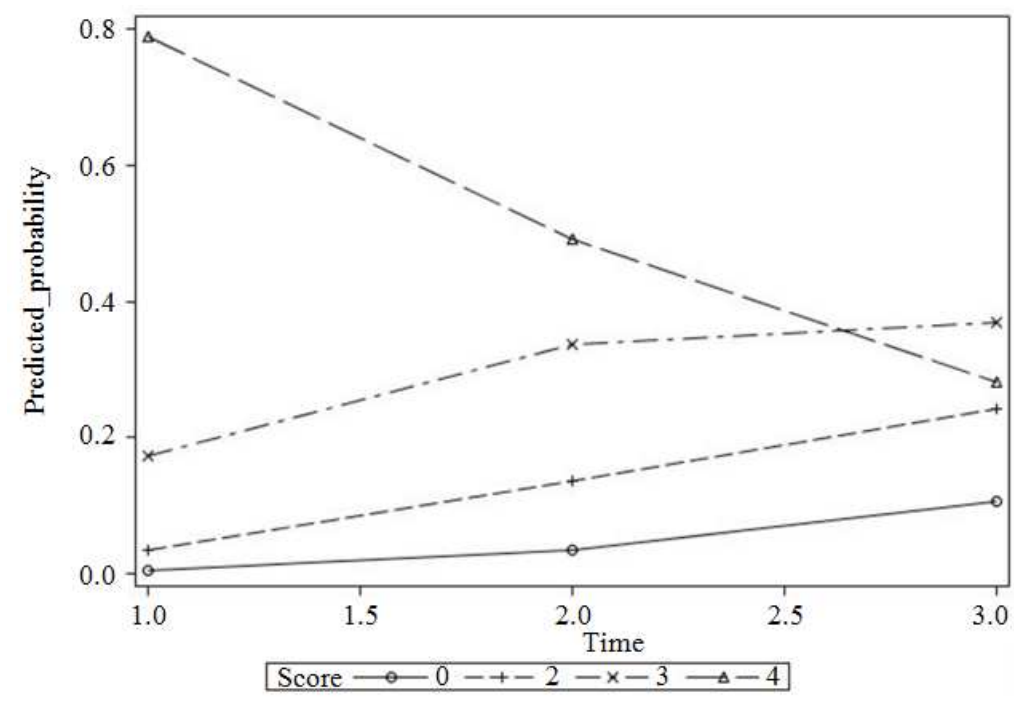

Fig. 2. Predicted probabilities of scores for lesion number 


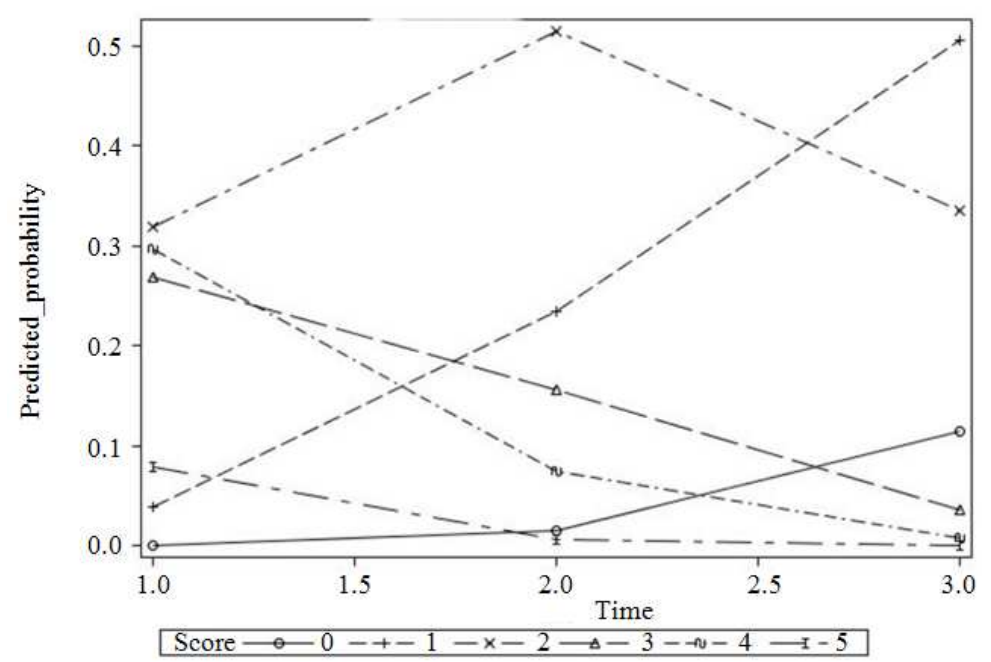

Fig. 3. Predicted probabilities of scores for lesion severity

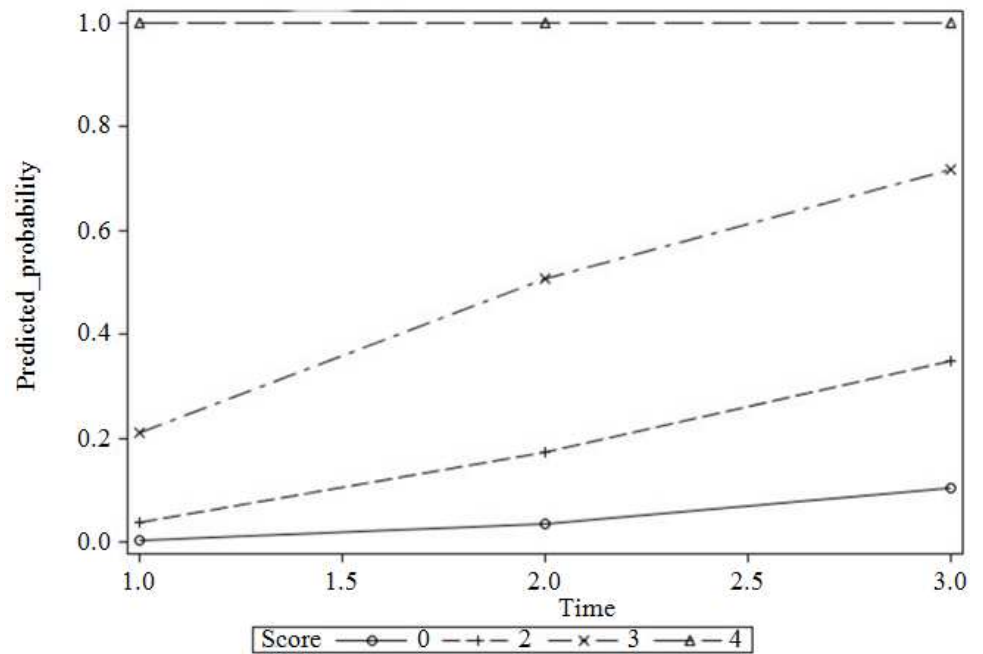

Fig. 4. Predicted cumulative probabilities of scores for lesion number

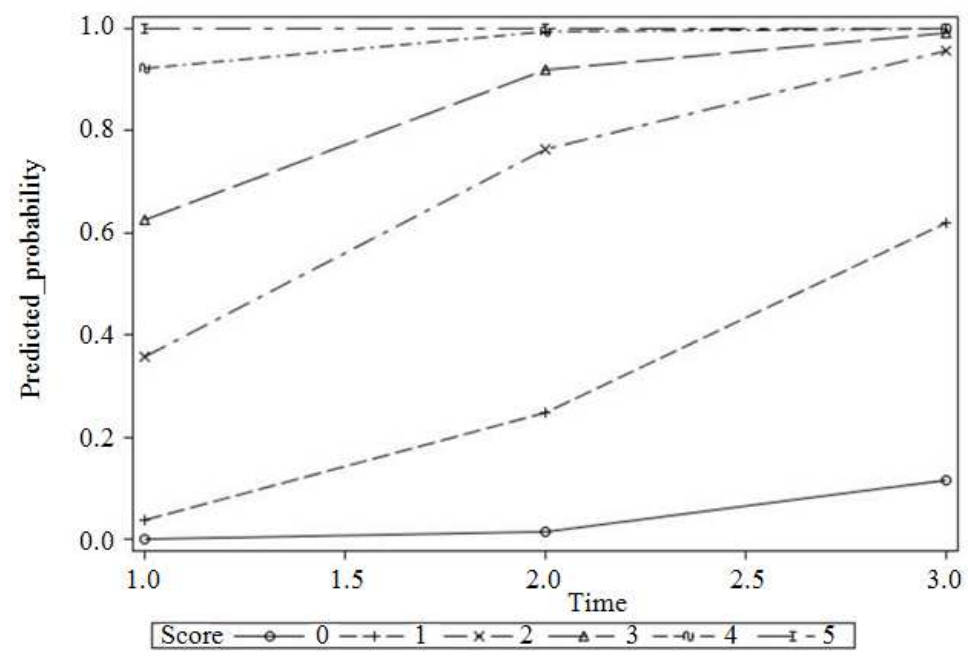

Fig. 5. Predicted cumulative probabilities of scores for lesion severity 


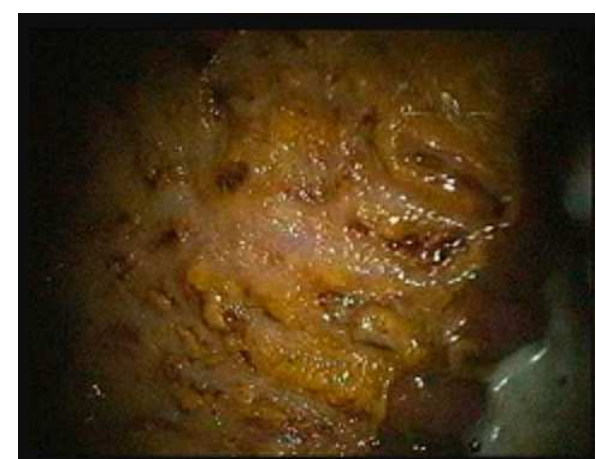

(A)

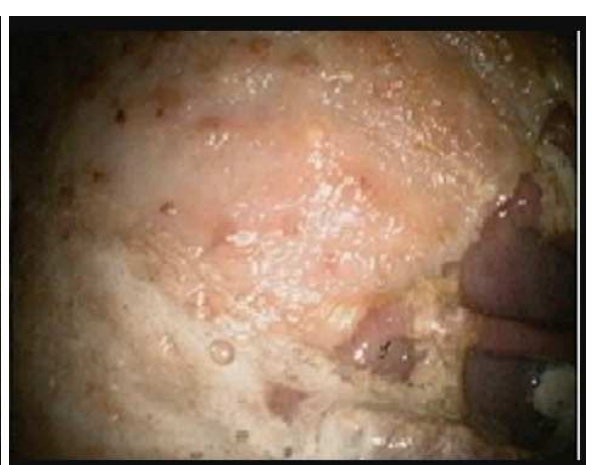

(B)

Fig. 6. Gastroscopic view at T1 (A) and T3 (B) of one of the horses of the study

\section{Discussion}

To date, no data reporting the efficacy of a feed supplement similar to the one administered in this study are available. The horses selected for the study were representative of the typical population affected by EGUS, i.e., high concentrates fed horses in training. Localisation, number and severityof the gastric lesions observed were consistent with previous studies (Ferrucci et al., 2003a; Roy et al., 2005; Bell et al.,2007; Tamzali et al., 2011).

Statistical analysis showed that administration of the supplement reduces significantly $(p<0.01)$ the scores for both number and severity of gastric lesions (Fig. 6). Scores improvement could be explained with the buffering effect of thosecomponents such as alfalfa hay (Husted et al., 2008), magnesium hydroxide and calcium carbonate (Clark et al., 1996). Besides, there are also other nutrients, such as threonine, Glycirrizaglabra (liquorice), Aloe vera, antioxidant factors and mucilages, that may have a protective effect on the gastric mucosa. Threonine is an amino acid involved in the production of protective mucus at the gastro-enteric level. Studies on piglets (Law et al., 2007) report that a lack in threonine represents a limiting factor for mucus production.Liquorice is included in the feed supplement in form of deglycyrrhizinated root extract, to prevent the occurrence of the systemic hypertension effects of liquorice. A study conducted in 1985 on 190 human patients, concluded that the substance is as effective as anti-acids and cimetidine in the treatment of duodenal chronic ulcers (Kassir, 1985). Several studies in human medicine and on other species proved theefficacy of liquorice as anti-ulcerogenic and gastro-protective factor (Guslandi, 1985; Aslam et al., 2015). The antiulcerogenic activity of liquorice extract results in the suppression of acid secretion and in an increase of mucine secretion. Liquorice also promotes the release of PGE2. Antioxidant action is due to its flavonoid content (Khayyal et al., 2001). Besides, it was reported that flavonoid could inhibit protonic-pump in the glandular mucosa of the stomach (Beil et al., 1995). Studies conducted on human patients (Langmead et al., 2006) and on rats (Eamlamnam et al., 2006) hypothesize an anti-ulcerogenic activity of Aloe vera, due to its antiinflammatory, cytoprotective and mucus-stimulating effects. Anti-inflammatory effects of Aloe vera were demonstrated in horses as well (Lans et al., 2006). Aloe could act increasing the perfusion of gastric mucosa, reducing vasoconstriction and promoting angiogenesis, facilitating the healing of ulcers. Finally, mucilages (Pectin, Guar, Psyllium and fenugreek), when in an acid environment, form a viscous gel that protects the mucosa from the effects of acidity (Murray and Grady, 2002; Ferrucci et al., 2003b; Lans et al., 2006).

One possible limit of the present study is that it was conducted as a field trial, in theabsence of a control group. This condition doesn't allow to rule out the possibility that the lesions could have improvedspontaneously (Murray et al., 1997). However, the management of the horses was not changed throughout the study. Therefore, EGUS predisposing factors, such as training and competition, feeding a diet high in concentrates and low in fibre and box stabling were maintained during the whole period of treatment, suggesting that the administration of the supplement mayhave had a positive effect on ulcers healing.

\section{Conclusion}

In conclusion, the administration of Gastrocure was effective in reducing the number and severity of ulcerative lesions in horses affected by EGUS. These results suggest that this product couldbe included in the treatment protocol of EGUS, according to each individual case, either alone or as an adjuvant in anti acid treatment or during the period when anti acidsarediscontinued, in order to prevent the "rebound effect".

\section{Acknowledgement}

The Authors wish to acknowledge Dr. Fabio Maria Colombo (Department of Health, Animal Science and Food Safety, Universitàdegli Studi di Milano) for helping with statistical evaluation and Dr. Armida 
Barelli (Istituto Farmaceutico Candioli, Italy), for technical support during the trial.

\section{Funding Information}

The project has been funded by Istituto Farmaceutico Candioli which is the company that has patent on Gastrocure.

\section{Author Contributions}

All authors were actively involved in all stage of the work. The manuscript it has been read and approved by all authors.

\section{Conflict of Interest}

The authors have no personalfinancial or nonfinancial competing interest in the product.

\section{References}

Andrews, F.M. and J.A. Nadeau, 1999. Clinical syndromes of gastric ulceration in foals and mature horses. Equine Vet. J. Supp., 29: 30-33.

Andrews, F.M., B.R. Buchanan, S.B. Elliott, R.A.M. Al Jassim and C.M. McGowan et al., 2008. In Vitro effects of hydrochloric and lactic acids on bioelectric properties of equine gastric squamous mucosa. Equine Vet. J., 40: 301-305.

Aslam, B., T. Awan, I. Javed, T. Khaliq and J.A. Khan et al., 2015. Gastroprotective and antioxidant potential of Glycyrrhizaglabra on experimetally induced gastric ulcer in albino mice. Int. J. Curr. Microbiol. Applied. Sci., 4: 451-460.

Beil, W., C. Birkholz and K.F. Sewing, 1995. Effects of flavonoids on parietal cell acid secretion, gastric mucosal prostaglandin production and helicobacter pylori growth. Arzneimittel-Forschungm, 45: 697-700.

Bell, R.J.W., J.K. Kingston, T.D. Mogg and N.R. Perkins, 2007. The prevalence of gastric ulceration in racehorses in New Zealand. New Zeal Vet. J., 55: 13-18.

Buchanan, B.R. and F.M. Andrews, 2003. Treatment and prevention of equine gastric ulcer syndrome. Vet. Clin. Equine Pract., 19: 575-597.

Clark, C.K., A.M. Merritt, J.A. Burrow and C.K. Steible, 1996. Effect of aluminuim hydroxide/magnesium hydroxide antacid and bismuth subsalicylate on gastric pH in horses. J. Am. Vet. Med. Assoc., 208: 1687-1691.

Dionne, R.M., A. Vrins, M.Y. Doucet and J. Parè, 2003. Gastric ulcers in standardbred racehorses: Prevalence, lesion descriptionand risk factors. J. Vet. Intern. Med., 17: 218-222.
Eamlamnam, K., S. Patmuraj, N. Visedopas and D. Thong-Ngam, 2006. Effects of Aloe vera and sucralfate on gastric microcirculatory changes, cytokine levels and gastric ulcer healing in rats. World J. Gastroentero, 12: 2034-2039.

Ferrucci, F., E. Zucca, V. Di Fabio, C. Croci and F. Tradati, 2003a. Gastroscopic findings in 63 standardbred racehorses in training.Vet. Res. Commun., 27: 759-762. PMID: 14535515

Ferrucci, F., E. Zucca, C. Croci, V. Di Fabio and E. Ferro, 2003b. Treatment of gastric ulceration in 10 standardbred racehorses with a pectin-lecithin complex. Vet. Rec., 152: 679-681.

Guslandi, M., 1985. Ulcer-healing drugs and endogenous prostaglandins. Int. J. Clin. Pharm. Therapy Toxicol., 23: 398-402. PMID: 2864318

Hellings, I.R. and S. Larsen, 2014. ImproWin ${ }^{\circledR}$ in the treatment of gastric ulceration of the squamous mucosa in trotting racehorses. Acta. Vet. Scand, 56: 13-13. DOI: 10.1186/1751-0147-56-13

Hepburn, R.J., 2001. Gastric ulceration in horse. Practice, 33: 116-124.

Huff, N.K., A.D. Auer, F. Garza, M.L. Keowen and M.T. Kearney et al., 2012. Effect of sea buckthorn berries and pulp in a liquid emulsion on gastric ulcer scores and gastric juice $\mathrm{pH}$ in horses. J. Vet. Intern Med., 26: 1186-1191. DOI: $10.1111 / \mathrm{j} .1939-1676.2012 .00975 . \mathrm{x}$

Hunfeld, N.G.M., W.P. Geus and E.J. Kuipers, 2007. Systematic review: Rebound acid hypersecretion after therapy with proton pump inhibitors. Aliment Pharm. Therap., 25: 39-46. PMID: 17229219

Husted, L., L.C. Sanchez, S.N. Olsen, K.E. Baptiste and A.M. Merrit, 2008. Effect of paddock vs. stall housing on 24 hour gastric $\mathrm{pH}$ within the proximal and ventral equine stomach. Equine Vet. J., 40: 337-341.

Jonsson, H. and A. Egenvall, 2006. Prevalence of gastric ulceration in swedishst and ardbreds in race training. Equine Vet. J., 38: 209-213. PMID: 16706273

Kassir, Z.A., 1985. Endoscopic controlled trial of four drug regimens in the treatment of chronic duodenal ulceration. Ir. Med. J., 78: 153-6. PMID: 3891678

Khayyal, M.T., M.T. El-Ghazaly, S.A. Kenawy, M. Seif-Al Naser and L.G. Mahranet al., 2001. Antiulcerogenic effect of some gastro intestinally acting plant extracts and their combination. Arzneimittel-forsch, 51: 545-553.

Langmead, L., R.M. Feakins, S. Goldthorpe, H. Holt and E. Tsironi et al., 2006. Randomized, double-blind, placebo-controlled trial of oral aloe vera gel for active ulcerative colitis. Aliment Pharm. Therap., 19: 341-349. DOI: 10.1111/j.1365-2036.2004.01902.x

Lans, C., N. Turner, G. Brauer, G. Lourenco and K. Georges, 2006. Ethno veterinary medicines used for horses in trinidad and in British Columbia, Canada. J. Ethnobiol. Ethnomed. 
Law, G.K., R.F. Bertolo, A. Adjiri-Awere, P.B. Pencharz and R.O. Ball, 2007. Adequate oral threonine is critical for mucin production and gut function in neonatal piglets. Am. J. Physiol. Gastrointest Liver Physiol., 292: 1293-1301.

Le Jeune, S., J. Nieto, J. Dechant and J. Snyder, 2009. Prevalence of gastric ulcers in thoroughbred broodmares in pasture. Vet J., 181: 251-255.

MacAllister, C.G., F.M. Andrews, E. Deegan, W. Ruoff and S.G. Olovson, 1997. A scoring system for gastric ulcers in the horse. Equi. Vet. J., 29: 403-433.

Malmkvist, J., J.M. Poulsen, N. Luthersson, R. Palme and J.W. Chistensen et al., 2012. Behavior and stress responses in horses with gastric ulceration. Applied Anim. Behav. Sci., 142: 160-167.

Murray, M.J., C. Grodinsky, C.W. Anderson, P.F. Radue and R. Schmidt, 1989. Gastric ulcers in horses: A comparison of endoscopic findings in horses with and without clinical signs. Equine Vet. J., 21: 68-72. DOI: 10.1111/j.2042-3306.1989.tb05659.x

Murray, M.J., M.L. Haven, E.S. Eichorn, G.J. Hickey and J. Eagleson, 1997. The effects of omeprazole on healing of natural-occurring gastric ulcers in thoroughbred race horses. Equine. Vet. J., 28: 368-374.

Murray, M.J. and T.C. Grady, 2002. The effect of a pectin-lecithin complex on prevention of gastric mucosal lesions induced by feed deprivation in ponies. Equine. Vet. J., 34: 195-198.
Nadeau, J.A., F.M. Andrews, C.S. Patton, R.A. Argenzio and A.G. Mathew et al., 2003. Effects of hydrochloric, acetic, butyric and propionic acids on pathogenesis of ulcers in the nonglandular portion of the stomach of horses. Am. J. Vet. Res., 64: 404-412.

Nieto, J.E., J.R. Snyder, N.J. Vatistas and J.H. Jones, 2009. Effect of gastric ulceration on physiologic responses to exercise in horses. Am. J. Vet. Res., 70: 787-795. DOI: 10.2460/ajvr.70.6.787

Roy, M.A., A. Vrins, G. Beauchamp and M.Y. Doucet, 2005. Prevalence of ulcers of the squamous gastric mucosa in Standardbred horses. J. Vet. Intern. Med., 19: $744-750$

Sykes, B.W., M. Hewetson, R.J. Hepburn, N. Luthersson and Y. Tamzali, 2015. European college of equine internal medicine-equine gastric ulcer syndrome in adult horses. J. Vet. Intern. Med., 201: 1288-1299.

Tamzali, Y., C. Marguet, N. Priymenko and F. Lyazrhi, 2011. Prevalence of gastric ulcer syndrome in highlevel endurance horses. Equin. Vet. J., 43: 141-144. DOI: $10.1111 / \mathrm{j} .2042-3306.2010 .00129 . x$

Venner, M., S. Lauffs and E. Deegen, 1999.Treatment of gastric lesions in horses with pectin-lecithin complex. Equine Vet. J. Supp., 29: 91-96.

White, G., S.R. McClure, R. Sifferman, J.E. Holste and C. Fleishmanet al., 2007. Effects of short-term light to heavy exercise on gastric ulcer development in horses and efficacy of omeprazole paste in preventing gastric ulceration. J. Am. Vet. Med. Assoc., 230: 1680-1682. 